\title{
Pulmonary fibrosis with predominant CD8 lymphocytic alveolitis and anti-Jo-1 antibodies
}

\author{
A. Sauty*, Th. Rochat*, O.D. Schoch++, J. Hamacher*, A-M. Kurt**, J-M. Dayer+, L.P. Nicod*
}

Pulmonary fibrosis with predominant CD8 lymphocytic alveolitis and anti-Jo-1 antibodies. A. Sauty, Th. Rochat, O.D. Schoch, J. Hamacher, A-M. Kurt, J-M. Dayer, L.P. Nicod. CERS Journals Ltd 1997.

ABSTRACT: Interstitial lung disease (ILD) is a complication of polymyositis (PM) and dermatomyositis (DM). It often manifests itself in association with myositis-specific antisynthetase autoantibodies, among which anti-Jo-1 antibodies are the most commonly encountered. In contrast, ILD associated with anti-Jo-1 antibodies without muscle involvement is rare and not well characterized.

We report four patients presenting with ILD associated with anti-Jo-1 antibodies. Histological findings of transbronchial biopsies disclosed a pattern consistent with nonspecific interstitial pneumonitis, a CD8+ lymphocytosis was found in bronchoalveolar lavage. Only one of these patients developed an "antisynthetase syndrome" with PM, after nearly 2 yrs of severe ILD. The clinical conditions of all four cases showed stabilization or improvement when cyclosporine was added to their immunosuppressive treatment.

These cases confirm that a CD8+ lymphocytic interstitial lung disease may be the first, and sole manifestation of autoimmune disease associated with anti-Jo-1 antibodies. Furthermore, they suggest that this form of interstitial lung disease apparently has a poor response to steroids and cytotoxic drugs, but may respond to moderate doses of cyclosporine and azathioprine in addition to low doses of steroids.

Eur Respir J 1997; 10: 2907-2912.
*Division of Pneumology, Dept of Internal Medicine, and **Dept of Pathology, University Hospital, Geneva, Switzerland. +Division of Immunology and Allergy, Dept of Internal Medicine, ${ }^{++}$Dept of Internal Medicine, St Gallen Hospital, Switzerland.

Correspondence: L.P. Nicod

Division of Pneumology

University Hospital

1211 Geneva 14

Switzerland

Keywords: Anti-Jo-1

CD8+ lymphocyte

inflammatory myositis

interstitial lung disease

Received: October 211996

Accepted after revision August 191997
Development of interstitial lung disease (ILD) in patients with polymyositis (PM) and dermatomyositis (DM) has been well described, and has been shown to increase morbidity and mortality in patients with myositis [1-3].

Antisynthetase antibodies (AAs) are autoantibodies to aminoacyl transfer ribonucleic acid (tRNA) synthetases involved in the binding of amino acids to their tRNAs. Almost exclusively found in patients with PM and DM, they are the most frequent myositis-specific autoantibodies $[3,4]$. Among the five AAs known, anti-Jo-1 antibodies (anti-histidyl-tRNA synthetase) are the most common, and are found in $20-30 \%$ of patients with myositis, most often seen in patients with PM and occasionally in those with DM [5-8]. Fifty to $100 \%$ of patients with AAs, particularly anti-Jo-1, have been shown to develop fibrosing alveolitis [3, 6-9]. Other primary lung manifestations associated with myositis and anti-Jo-1 include organizing pneumonia [10], acute respiratory distress syndrome (ARDS) [11] and capillaritis with diffuse alveolar haemorrhage [12]. Fever, Raynaud's phenomenon, arthritis and mechanic's hands have all been found to have a strong association with myositis accompanied by ILD, are manifestations of the "anti-synthetase syndrome" [3, 9]. The term "mechanic's hands" refers to hyperkeratosis, hyperpigmentation with scaling and fissuring on the lateral sides of the fingers [4].

Fibrosing alveolitis has rarely been described as an initial presentation of the antisynthetase syndrome or as an isolated form associated with only anti-Jo-1 antibodies [7,
13-16]. We report four patients who developed ILD with a histological pattern compatible with a nonspecific interstitial pneumonitis. The differential cell count performed on bronchoalveolar lavages (BALs) consistently revealed lymphocytosis with a marked predominance of CD8+ Tcells. From 2.5-19 months after the onset of symptoms, anti-Jo-1 antibodies were found in all cases. Addition of cyclosporine (CsA) and azathioprine (AZA) to low-dose corticosteroid led to stabilization or improvement of the respiratory disease.

\section{Case reports}

\section{Case 1}

An otherwise healthy $60 \mathrm{yr}$ old female patient developed asthenia, rapidly progressive exertional dyspnoea and a dry cough in June 1993 (table 1). The patient was in good physical condition, showing no signs of fever, skin involvement or arthritis. Fine crackles were noted at both lung bases but no signs of cardiac insufficiency were found. No history of allergies or occupational diseases were reported.

Haematology, renal and hepatic parameters, and creatine kinase (CK) were normal. The patient was negative for human immunodeficiency virus (HIV) antibodies. 
Table 1. - Characteristics of patients

\begin{tabular}{lcccc}
\hline Characteristics & Case 1 & Case 2 & Case 3 & Case 4 \\
\hline Age yrs & 60 & 59 & 60 & 67 \\
Sex & F & F & M & F \\
Duration of symptoms & 2.5 & 7.5 & 19 & 8 \\
$\quad$ before diagnosis of ILD & & & & \\
$\quad$ with anti-Jo-1 months & & & & \\
Antisynthetase syndrome & - & - & + & - \\
Exertional dyspnoea & $+/+$ & $+/+$ & $+/+$ & + \\
Dry cough & $+/+$ & $+/-$ & $+/+$ & + \\
Fever & $-/-$ & $\pm /-$ & $+/-$ & - \\
Myalgia & $-/-$ & $-/-$ & $-/+$ & - \\
Arthralgia & $-/-$ & $+/-$ & $-/-$ & - \\
Raynaud's phenomenon & $-/-$ & $-/-$ & $-/-$ & - \\
\hline
\end{tabular}

Values are presented prior/at the time of diagnosis of interstitial lung disease (ILD) associated with anti-Jo-1 antibody. F: female; M: male; +: present; -: absent; \pm : intermittent.

Immunological tests are summarized in table 2. Chest radiography disclosed a bibasal alveolo-interstitial infiltrate and pulmonary functions showed pure restriction (total lung capacity (TLC): $66 \%$ of normal values). The transfer factor of the lung for carbon monoxide $(T \mathrm{~L}, \mathrm{CO})$ was $57 \%$ of the predicted value. BAL analysis is reported in table 2, and BAL cultures were free of pathogens. Histology performed on transbronchial biopsies (TBBs) revealed a chronic interstitial pneumonitis, with predominantly T-lymphocytic infiltrates in alveolar septa.

Because of the suspicion of idiopathic pulmonary fibrosis with rapid clinical deterioration, administration of deflazacort $0.6 \mathrm{mg} \cdot \mathrm{kg}^{-1} \cdot \mathrm{day}^{-1}$ (equivalent to $0.5 \mathrm{mg} \cdot \mathrm{kg}^{-1} \cdot \mathrm{day}^{-1}$ prednisone) was started. The dose was increased to 1.6 $\mathrm{mg} \cdot \mathrm{kg}^{-1} \cdot \mathrm{day}^{-1}$ when deterioration set in. Detection tests for anti-Jo-1 antibodies, performed for the first time 2.5 months after the onset of symptoms, were positive. Since no improvement was observed after having given 500 mg.day ${ }^{-1}$ methyl prednisone for three consecutive days, CsA was added (serum CsA $200 \mu \mathrm{g} \cdot \mathrm{mL}^{-1}$ was achiev- ed) resulting in good clinical, radiological and functional responses, and the disappearance of anti-Jo-1 antibodies. Sev- enteen months after the first symptoms, clinical degradation occurred after withdrawal of CsA. Repeat bronchoscopy confirmed BAL lymphocytosis (45\%) with a low CD4/CD8 ratio (0.44). CK and aldolase were normal, lactate dehydrogenase (LDH) was increased at $688 \mathrm{IU} \cdot \mathrm{L}^{-1}$ (normal: 204-412 IU.L-1). Gancyclovir was added to the treatment because of positive cytomegalovirus (CMV) early antigen in BAL, in the absence of viral inclusions. CsA was reintroduced and corticosteroids were temporarily increased with progressive improvement of both blood gases and vital capacity for the duration of the follow-up (fig. 1). The TLC and the TL,CO were 104 and $103 \%$ pred, respectively.

\section{Case 2}

A $59 \mathrm{yr}$ old woman suffering from ischaemic and hypertensive cardiopathy presented since April 1994 with progressive asthenia, exertional dyspnoea, cough and multiple arthralgias (shoulders, elbows, hands, wrists, knees) without arthritis or Raynaud's phenomenon. For 2 yrs, she had owned exotic birds. At physical examination, she was afebrile and eupneic at rest. No signs of cardiac insufficiency, arthritis or cutaneous involvement were noted. Bibasal fine crackles were noticed.

The platelet count was $327 \mathrm{~g} \cdot \mathrm{L}^{-1}$ and $\mathrm{LDH}$ was 654 IU.L $\mathrm{L}^{-1}$. Other haematological values as well as hepatic and renal functions were normal. Immunological findings are reported in table 2. Chest radiographs demonstrated a bibasal alveolo-interstitial infiltrate. The computed tomography (CT) scan confirmed the presence of focal infiltrates with an acinar pattern, some of which were restricted to the subpleural area. A restrictive syndrome (TLC: 59\% pred) with static air trapping was found and the TL,CO was $25 \%$ pred. Differential cell count of BAL is shown in table 2 , and no pathogens were found in BAL cultures. TBBs displayed interstitial pneumonitis with lymphocytic infiltrates (fig. 2a).

Table 2. - Immunological parameters, bronchoalveolar lavage (BAL) cellular composition at the time of first symptoms and of diagnosis of interstitial lung disease (ILD) associated with anti-Jo-1 antibodies

\begin{tabular}{|c|c|c|c|c|c|}
\hline & Normal values & Case 1 & Case 2 & Case 3 & Case 4 \\
\hline \multicolumn{6}{|l|}{ Immunology } \\
\hline Sedimentation rate $\mathrm{mm} \cdot \mathrm{h}^{-1}$ & $0-20$ & $42 / 36$ & $16 / 12$ & $76 / 46$ & 58 \\
\hline $\mathrm{C}$-reactive protein $\mathrm{mg} \cdot \mathrm{L}^{-1}$ & $<3$ & $26.6 / 36.2$ & $65 / 3.6$ & NA/5.9 & 9 \\
\hline Antinuclear antibodies dilutions* & $<80$ & $<40 /<40$ & $<80 /<80$ & $80^{\dagger} /<40$ & $<40$ \\
\hline Anti-DNA & & $-/-$ & -/NA & $-\grave{\dagger} /-$ & - \\
\hline ANCA & & $-/-$ & $-/-$ & $-\dagger / \mathrm{NA}$ & - \\
\hline Antiribonucleoproteins dilutions* & $<2$ & $-/ 16$ & $-/ 16$ & NA/8 & - \\
\hline Anti-Jo- $1^{\dagger}$ & & $\mathrm{NA} /+$ & $-/+$ & $-/+$ & + \\
\hline Precipitins & & $-/-$ & $-1-$ & -/NA & - \\
\hline \multicolumn{6}{|l|}{ BAL } \\
\hline$\times 10^{4}$ cells $\cdot \mathrm{mL}^{-1}$ & $13 \pm 2$ & $43 / 30$ & $37 / 13$ & $56 / 58$ & 33 \\
\hline Macrophages \% & $85 \pm 1.6$ & $12 / 32$ & $28 / 29$ & $2.5 / 49$ & 23 \\
\hline Lymphocytes \% & $1.5 \pm 2.5$ & $80 / 53$ & $51 / 53$ & $66 / 48$ & 66 \\
\hline PMNs & $1.6 \pm 0.7$ & $3 / 7$ & $10 / 9$ & $2 / 2$ & 5 \\
\hline Eosinophils \% & $0.19 \pm 0.06$ & $4 / 5$ & $11 / 10$ & $0 / 1$ & 6 \\
\hline Basophils \% & $<1$ & $0 / 2$ & $0 / 0$ & $0 / 0$ & 0 \\
\hline Epithelial cells \% & $<1$ & $1 / 1$ & $0 / 0$ & $29 / 0$ & 0 \\
\hline CD4/CD8 & $2.2 \pm 0.3$ & $0.15 / 0.18$ & $0.16 / 0.28$ & $0.21 / 0.1$ & 0.63 \\
\hline
\end{tabular}

Values are presented prior to/at time of diagnosis of ILD associated with anti-Jo-1 antibody. Normal BAL values are presented as mean \pm SE. Anti-DNA: antibodies against native deoxyribonucleic acid; ANCA: antineutrophil cytoplasmic antibodies; PMNs: polymorphonuclear neutrophils; NA: not available; -: negative; +: positive; *: serum dilutions when antibodies are still detectable $\ddagger$ : The anti-Jo-1 antibodies were detected by Quanta Lite Jo-2-ELISA (Inova Diagnostics. Inc; San Diego, CA, USA). ${ }^{\dagger}$ : done after the start of administration of steroids. (Normal BAL values from [17]). 

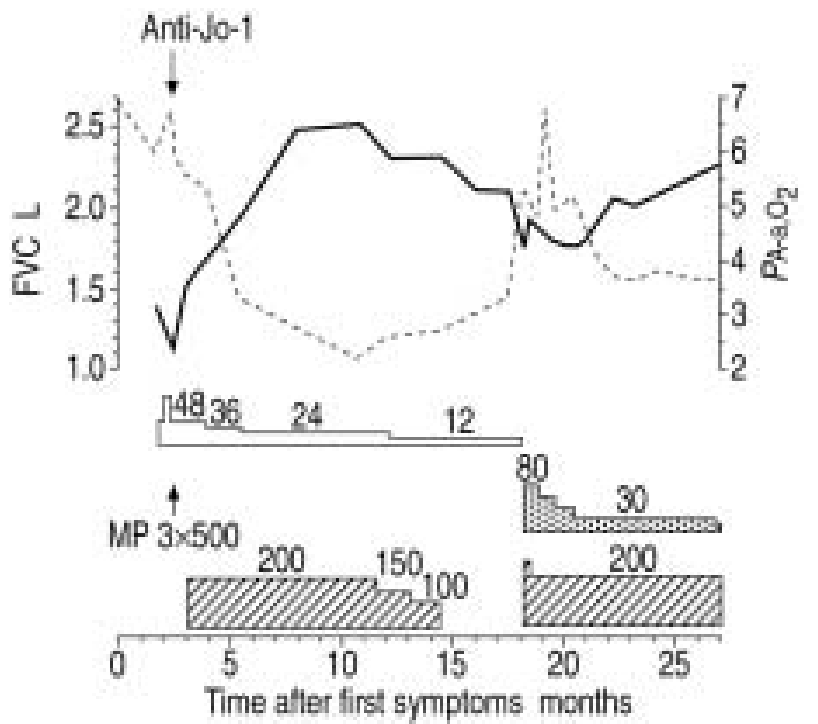

Fig. 1. - Evolution of lung function parameters in a patient (case 1) with interstitial pneumonitis associated with anti-Jo-1 antibodies in response to immunosuppressive drugs. ——: forced vital capacity $(\mathrm{FVC}) ;---$ : alveolar-arterial pressure difference of oxygen $\left(P \mathrm{~A}-\mathrm{a}, \mathrm{O}_{2}\right)$, given in absolute values. $\square$ : deflazacort $(0.6 \mathrm{mg}$ corresponds to $0.5 \mathrm{mg}$ prednisone); $1:$ : prednisone; $\overparen{Z}$ : cyclosporine. MP $3 \times 500$ : methyl prednisolone, $500 \mathrm{mg}$ on three consecutive days. Values given on the figure represent the dose administered, in mg.day ${ }^{-1}$.

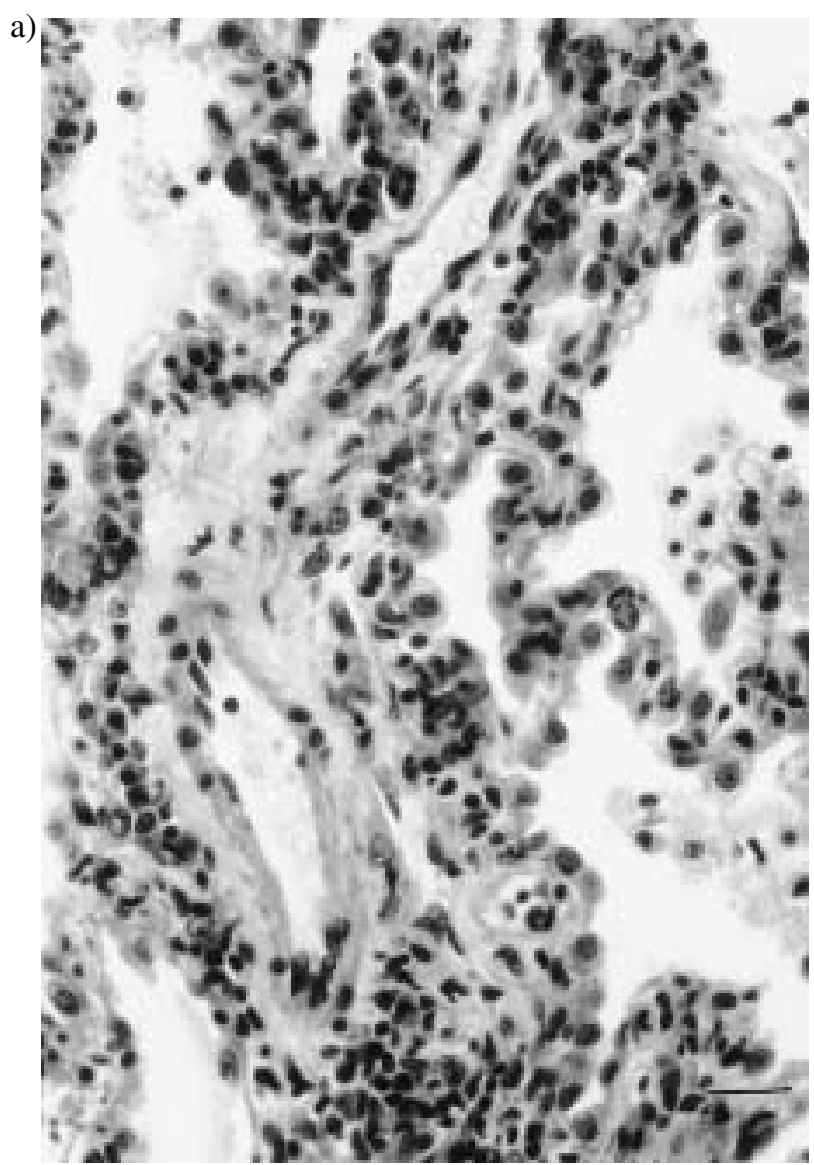

Despite negative precipitins, particularly avian precipitins, allergic alveolitis was suspected. Administration of prednisone $\left(1 \mathrm{mg} \cdot \mathrm{kg}^{-1} \cdot \mathrm{day}^{-1}\right)$ was started with initial good clinical and functional responses. However, following the reduction of prednisone to $10 \mathrm{mg} \cdot \mathrm{day}^{-1}$, the patient's condition worsened despite the eviction of birds. The detection test for the presence of anti-Jo-1 autoantibodies was performed 7.5 months after the onset of symptoms and was found to be positive. A new BAL confirmed predominant CD8 lymphocytosis, and TBBs disclosed nonspecific interstitial pneumonitis with fibrosis and lymphoplasmocytic infiltrates (fig. 2b). CK and aldolase were within the normal range. AZA $\left(100{\left.\mathrm{mg} \cdot \mathrm{day}^{-1}\right)}^{-1}\right.$ and CsA ( $2 \mathrm{mg} \cdot \mathrm{kg}^{-1} \cdot \mathrm{day}^{-1}$ divided in two doses $)$ were then added with progressive improvement of forced expiratory volume in one second and forced vital capacity (augmentation of $790 \mathrm{~mL}$ and $630 \mathrm{~mL}$, respectively) during the next 7 months of follow-up. The TLC had normalized to reach $92 \%$ pred while the $T \mathrm{~L}, \mathrm{CO}$ remained low at $48 \%$. One year later, while the patient was receiving only low doses of steroids (prednisone $10 \mathrm{mg} \cdot \mathrm{day}^{-1}$ ) following the discontinuation of AZA and CsA, the TLC and the TL,CO decreased to 79 and $39 \%$, respectively. Despite the re-introduction of both immunosuppressors, the pulmonary function tests did not normalize but remained stable.

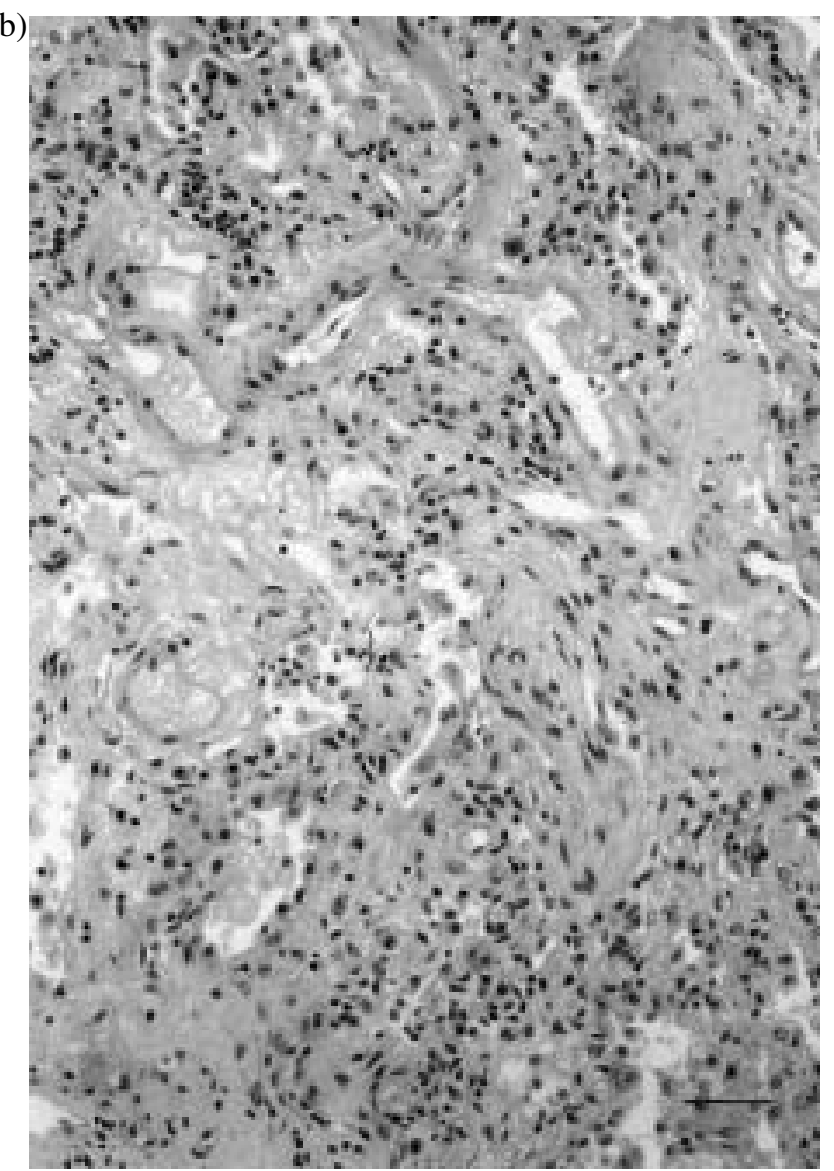

Fig. 2. - a) Early interstitial pneumonitis in a patient with anti-Jo-1 antibodies (case 2) showing an interstitial inflammatory infiltrate composed mainly of lymphocytes, associated with a diffuse hyperplasia of type II pneumocytes (Haematoxylin and eosin stain; internal scale bar $=25 \mu \mathrm{m}$ ). b) Late interstitial pneumonitis in a patient with anti-Jo-1 antibodies (case 2) characterized by a marked interstitial fibrosis and a residual lymphocytic inflammatory infiltrate (Haematoxylin and eosin stain; internal scale bar=50 $\mu \mathrm{m}$ ). 


\section{Case 3}

A 60 yr old man presented with a 3 month history of dyspnoea, dry cough and pulmonary bilateral infiltrates in March 1992. He was in good general condition, but bibasal fine crackles were reported without signs of cardiac insufficiency. Empirical antibiotic therapy was without effect.

Haematological and chemical values were normal. Immunological tests are summarized in table 2. Chest radiographs and pulmonary functions showed bibasal acinar infiltrates of lung fields and a restrictive syndrome, respectively (TLC: $66 \%$ of normal values). The TL,CO was at $38 \%$ of normal value. No pathogen was found in BAL (cellular composition in table 2). TBBs revealed lymphoid interstitial pneumonitis. Respiratory failure developed $48 \mathrm{~h}$ after bronchoscopy requiring long duration intubation. Administration of prednisone $1 \mathrm{mg} \cdot \mathrm{kg}^{-1} \cdot \mathrm{day}^{-1}$ (70 mg.day-1) was started in May 1992. In December 1992, Pneumocystis carinii and CMV pneumonitis occurred with the development of cutaneous Kaposi's sarcoma. The patient was negative for HIV1, HIV2 and human Tlymphotropic virus-1 antibodies. These intercurrent infections and the Kaposi syndrome were attributed to the immunosuppression. Therefore, corticosteroids were progressively reduced to $5 \mathrm{mg} \cdot \mathrm{day}^{-1}$ in June 1993 . At that time, pulmonary function tests and lung infiltrates on the CT scan deteriorated (fig. 3). The infiltrates were becoming more confluent and were still prominent subpleurally. CK level was $585 \mathrm{IU} \cdot \mathrm{L}^{-1}$ (normal: 5-150), that of LDH was $618 \mathrm{IU} \cdot \mathrm{L}^{-1}$ (normal: 204-412) and that of aldolases was $17.1 \mathrm{IU} \cdot \mathrm{L}^{-1}$ (normal: 0.6-9.4). The blood CD4+ lymphocytes count decreased transiently in the absence of an obvious viral origin to $431 \mathrm{cells} \cdot \mathrm{mm}^{-3}$. Prednisone was increased to $40 \mathrm{mg} \cdot \mathrm{day}^{-1}$ then to $70 \mathrm{mg} \cdot \mathrm{day}^{-1}$ with the addition of colchicine. In November 1993, the CD4+ count returned to normal $\left(1278 \cdot \mathrm{mm}^{-3}\right)$. Anti-Jo-1 antibodies

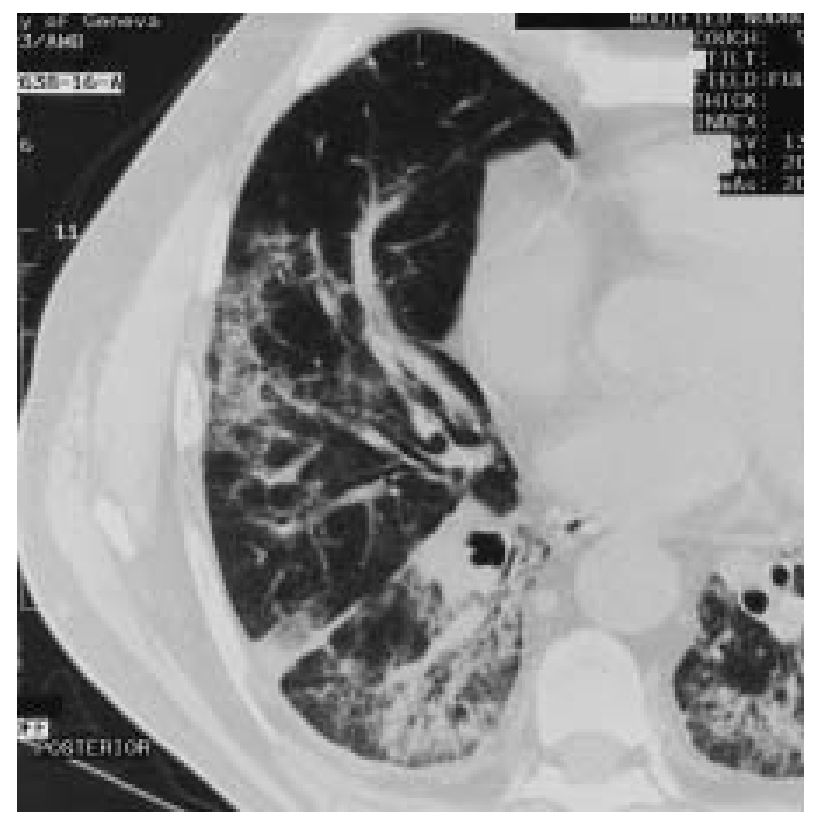

Fig. 3. - Computed tomography scan of an interstitial pneumonitis in a patient (case 3) with anti-Jo-1 antibodies showing subpleural infiltrates as well as more confluent consolidations in the apical segment of the right lower lobe. were then found to be present, while absent on a serum sample drawn at the onset of the disease, and analysed retrospectively. This prompted the diagnosis of ILD associated with anti-Jo-1. TLC was then at $44 \%$ and TL,CO at $38 \%$ pred.

In March 1994, the patient complained of an increasing disposition to dry cough with fever, proximal lower and upper limb pains accompanied by severe muscle weakness, and mechanic's hands. Elevated CK (1715 IU.L-1 $)$, LDH (721 IU.L $\left.{ }^{-1}\right)$ and aldolase (46.2 IU.L $\left.\mathrm{L}^{-1}\right)$ levels were found with a markedly increased titre of anti-Jo-1 antibodies. TBBs confirmed interstitial pneumonitis with more advanced fibrosis. Muscle biopsies and electromyography were consistent with PM leading to the diagnosis of the anti-synthetase syndrome. CsA was introduced combined

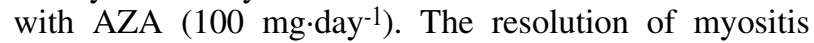
(based on clinical and biological criteria) was obtained within 2 months of treatment. Hypoxaemia gradually improved and there was also a slight improvement of pulmonary function tests and TL,CO with TLC reaching 47\% and $48 \%$ pred, respectively. AZA was then progressively tapered. Pulmonary condition stabilized and PM did not recur after 2 yrs of additional follow-up under minimal doses of prednisone $\left(7.5 \mathrm{mg} \cdot \mathrm{day}^{-1}\right)$ together with CsA, at serum levels aimed at $150 \mu \mathrm{g} \cdot \mathrm{mL}^{-1}$.

\section{Case 4}

A 67 yr old woman, with a history of mild childhood asthma, and hypertension treated with nifedipine for the last 5 yrs, was well until April 1994. The patient started to complain of dyspnoea on exertion and chest tightness. Bibasal infiltrates were noted and empirical treatment with antibiotics and diuretics were without benefit. The symptoms gradually increased over a period of 8 months. In November 1994, she was afebrile and in good general condition, eupneic at rest. Crackles at both lung bases were found on auscultation. Blood pressure was 160/90 $\mathrm{mmHg}$. There was a $2 / 6$ systolic murmur, but no signs of cardiac insufficiency.

Haematological and chemical values were unremarkable except for a slight increase in LDH (725 IU.L-1 $)$. Results of immunological tests are reported in table 2 . Bibasal interstitial infiltrates were displayed on a chest radiograph, and a mild restrictive syndrome was noticed (TLC: $70 \%$ pred). Analysis of BAL is shown in table 2. TBBs disclosed interstitial pneumonitis with fibrosis of alveolar walls and T-lymphocytic infiltrates. Based on these findings, similar to those reported in cases $1-3$, the presence of anti-Jo-1 antibodies was assessed and found to be positive (table 2).

During the following days, fever developed, while pulmonary functions and gas exchanges deteriorated rapidly. Alveolar infiltrates appeared on both sides. Infectious pneumonia was suspected and administration of empirical antibiotics was started. High-dose prednisolone (2 $\mathrm{mg} \cdot \mathrm{kg}^{-1} \cdot \mathrm{day}^{-1}$ ) was then added after BAL demonstrated a CD8+ T-cells alveolitis. Fever subsided promptly and antibiotics were discontinued. However, pulmonary functions and blood gas values remained unsatisfactory. TLC and TL,CO were $50 \%$ and $47 \%$ pred, respectively. Cyclophosphamide was then added to prednisone. 


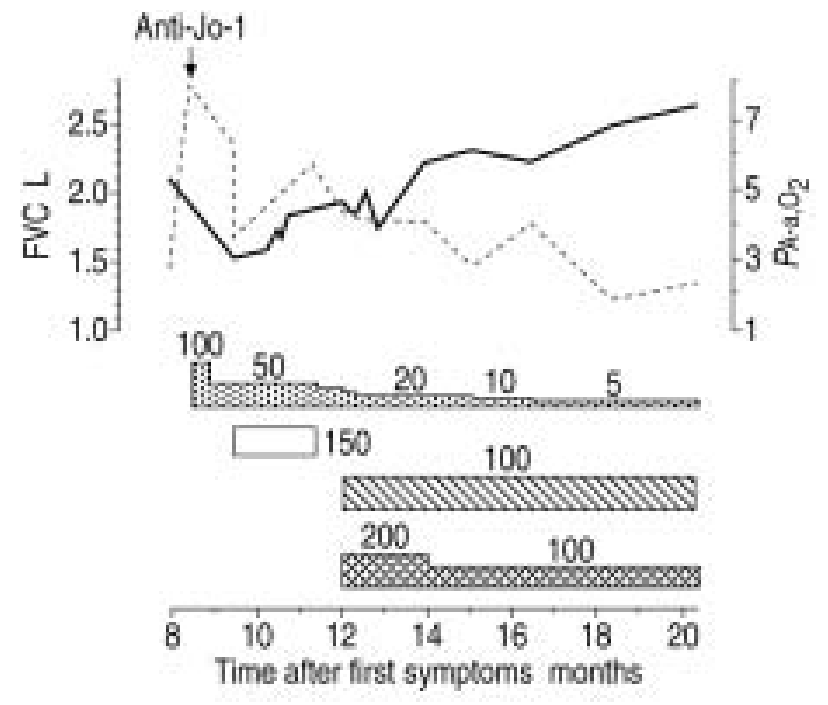

Fig. 4. - Evolution of lung function parameters in a patient (case 4) with interstitial pneumonitis is associated with anti-Jo-1 antibodies in response to immunosuppressive drugs. - $\longrightarrow$ FVC; $-\cdots: P \mathrm{~A}-\mathrm{a}, \mathrm{O}_{2}$, given

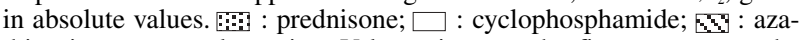
thioprine; $\$$ : cyclosporine. Values given on the figure represent the dose administered, in $\mathrm{mg} \cdot \mathrm{day}^{-1}$. For definitions, see legend to figure 1.

One month later, because of haemorrhagic cystitis, cyclophosphamide was discontinued. Despite the fact that anti-Jo-1 antibodies were only at the limit of detection, exertional dyspnoea was still present. CsA and AZA were then added with progressive clinical and functional improvement (fig. 4). Three months later, the patient complained of lower limb weakness. No myalgia, arthralgia or skin involvement were present. After reducing doses of prednisolone and CsA, symptoms disappeared leading to the diagnosis of steroid-induced myopathy. In October 1995, AZA was withdrawn. Clinical and pulmonary functions continued to improve (fig. 4). The TLC and TL,CO reached 78 and $74 \%$ pred. Anti-Jo-1 antibodies remained undetectable.

\section{Discussion}

We report four adult patients, three females and one male, who presented with ILD without muscle involvement and whose sera were positive for anti-Jo-1 autoantibodies but not for other autoantibodies. Initial clinical features were a dry cough and exertional dyspnoea. In all four cases, an increase in alveolar-arterial gradient of oxygen and a restrictive syndrome were found associated with bibasal infiltrates on chest radiographs. The histological pattern consisted of interstitial lymphocytic infiltrates and some degree of fibrosis. Treatment with CsA and AZA was very effective and allowed a marked reduction in steroid dosage.

ILD occurs frequently in PM and DM, although the prevalence differs in various studies [1-3, 9]. In myositis associated with AAs, among which anti-Jo-1 is far from the most frequently encountered, ILD frequency is high $[1,3,7-9,18]$ reaching $100 \%$, in the study of YoshiDa et al. [6]. These patients often present with the typical clinical features called "antisynthetase syndrome" which, apart from myositis, include ILD, fever, Raynaud's phenomenon, arthritis and mechanic's hands. This syndrome is predominant in white females, and has been found to have a strong association with certain histocompatibility leucocyte antigen (HLA) genes, i.e. HLA-DR3 and HLADRw52 in the case of anti-Jo-1 [3, 9, 19]. This HLA constellation was observed in three of our patients in whom it was evaluated, as two were HLA-DR3 and HLA-DR52 (cases 1 and 4), and one was HLA-DR 52 (case 3).

Although other forms of lung involvement have also been reported, such as ARDS [11] or organizing pneumonia [10], fibrosing alveolitis is predominant in AA-associated ILD. Its onset is often acute, and the response to corticosteroids is moderate with frequent relapse of the myositis when immunosuppression is tapered off. Five year survival is about $70 \%$ and is mostly limited by the pulmonary involvement [3].

Presentation of ILD with anti-Jo-1 autoantibodies appearing before myositis has been rarely reported in the literature. Two of $62(3 \%)$ patients with "cryptogenic" fibrosing alveolitis without myositis were reported by BERNSTEIN et al. [7]. The three cases reported by NASH et al. [13], Flammang D'Ortho et al. [15] and LöHr et al. [14] were two female patients (74 and 62 yrs old) and one male patient (67 yrs old), respectively, who developed ILD 8-12 months before myositis. Initial bilateral infiltrates were present in two cases while a unilateral infiltrate was seen in one. In all three patients, BAL revealed lymphocytosis (39-67\%). A low CD4/CD8 ratio (0.2) was found in the only case where it was looked for. Pooling these three patients with the present study, it appears that this syndrome has a predominance in females (female:male ratio $5: 2$ ) and occurs in the age range of 59-74 yrs. However, the syndrome has recently been described in a child with ILD associated with anti-Jo-1, the lung involvement preceding the appearance of an inflammatory myositis [16].

TBBs performed in our patients showed a thickening of interalveolar septa with lymphocytic infiltrates and type II pneumocytes hyperplasia. A mild interstitial fibrosis was usually present and worsened with time in case 3 . Organization of intra-alveolar exudates was found in one case (case 2).

In all cases, BAL analysis revealed lymphocytosis with very low $\mathrm{CD} 4 / \mathrm{CD} 8$ ratios. BAL procedures were performed at the time of first symptoms and later during the course of the disease because of deterioration of respiratory condition and/or suspicion of lung infection. In the 14 BALs performed, lymphocytosis (defined as $>20 \%$ lymphocytes in the blood) was found in 12 (range 26$80 \%$ ) while the CD4/CD8 ratio was decreased in all. The BAL in three patient revealed a mild increase in eosinophils and neutrophils.

Presence of autoantibodies such as AAs implicates humoral immunity. Whether AAs are pathogenic or not remains unclear [4]. Although anti-Jo-1 antibodies inhibit their target enzymes activity in vitro [20], it is probable that they do not have access to their intracytoplasmic antigen. Moreover, organ specificity is difficult to explain, as AAs are found in all type of cells.

High-dose prednisone, usually $1 \mathrm{mg} \cdot \mathrm{kg}^{-1} \cdot \mathrm{day}^{-1}$, is the first choice treatment for myositis [21], but the clinical response to steroids is often partial in patients with AAassociated myositis [22]. Other immunosuppressive approaches have been tried with disparate results, and have been reviewed recently by DALAKAS [21]. Some case reports have suggested the potential benefit of CsA in myositis $[23,24]$. CsA, as a first choice treatment, was effective 
and induced a faster response when compared to a historical control group treated with various immunosuppressive drugs [25].

ILD associated to myositis, particularly when AAs are present, may determine survival [2, 3, 9], and should be treated aggressively. The treatment of ILD associated with myositis is mainly extrapolated from clinical trials on idiopathic pulmonary fibrosis or collagen vascular disease-associated ILD and has been recently reviewed [26]. Clinical and functional responses have been shown with steroids alone [26] or in association with cyclophosphamide [27], AZA [28] or CsA [29]. CsA was found to be effective in association with steroid or even alone in patients with ILD (without myositis) particularly in those with a high lymphocytic count in BAL [30].

After the failure of high-dose steroids alone or in combination with cytotoxic drugs, CsA was added in all four patients: and in three combined with AZA. Three patients improved and one was stabilized under this regimen. Steroids could be markedly decreased and AZA withdrawn, except in one case. Serum CsA levels were carefully monitored and no renovascular side-effects were observed in our cases. Although the role of each drug cannot be determined, addition of CsA and AZA seemed to positively modify the clinical course of our patients and to allow the improvement of objective parameters such as chest radiography, pulmonary functions tests and blood gas values. However, long-term follow-up is needed to determine whether this amelioration is maintained, and whether these patients remain free of recurrence.

In conclusion, these data suggest that, in the presence of an interstitial lung disease with CD8+ lymphocytic alveolitis, anti-Jo-1 autoantibodies should be assessed as an inflammatory myositis as a full antisynthetase syndrome may be absent. This form of interstitial lung disease, as well as antisynthetases-associated myositis, has an apparently poor response to steroids and cytotoxic drugs, but may respond to moderate doses of cyclosporine and azathioprine in addition to low doses of steroids.

\section{References}

1. Hochberg MC, Feldman D, Stevens MB. Adult onset polymyositis/dermatomyositis: an analysis of clinical and laboratory features and survival in 76 patients with a review of the literature. Semin Arthritis Rheum 1986; 15: 168-178.

2. Arsura EL, Greenberg AS. Adverse impact of interstitial pulmonary fibrosis on prognosis in polymyositis and dermatomyositis. Semin Arthritis Rheum 1988; 18: 29-37.

3. Love LA, Leff RL, Fraser DD, et al. A new approach to the classification of idiopathic inflammatory myopathy: myositis-specific autoantibodies define useful homogeneous patient groups. Medicine 1991; 70: 360-374.

4. Targoff IN. Immune manifestations of inflammatory muscle disease. Rheum Dis Clin North Am 1994; 20: 857-880.

5. Nishikai M, Reichlin M. Heterogeneity of precipitating antibodies in polymyositis and dermatomyositis. Characterization of the Jo-1 antibody system. Arthritis Rheum 1980; 23: 881-888.

6. Yoshida S, Akizuki M, Mimori T, Yamagata H, Inada S, Homma M. The precipitating antibody to an acidic nuclear protein antigen, the Jo- 1 , in connective tissue diseases. Arthritis Rheum 1983; 26: 604-611.

7. Bernstein RM, Morgan SH, Chapman J, et al. Anti-Jo-1 antibody: a marker for myositis with interstitial lung disease. Br Med J 1984; 289: 151-152.
8. Hochberg MC, Feldman D, Stevens MB, Arnett FC, Reichlin M. Antibody to Jo-1 in polymyositis/dermatomyositis: association with interstitial pulmonary disease. $J$ Rheumatol 1984; 11: 663-665.

9. Marguerie C, Bunn CC, Beynon HLC, et al. Polymyositis, pulmonary fibrosis and autoantibodies to amino-tRNA synthetase enzymes. $Q J$ Med 1990; 77: 1019-1038.

10. Chan WM, Lau CS, Wang E, Peh WCG. Anti-Jo-1 syndrome presenting as cryptogenic organizing pneumonia. Respir Med 1995; 89: 639-641.

11. Clawson K, Oddis CV. Adult respiratory distress syndrome in polymyositis patients with the anti-Jo-1 antibody. Arthritis Rheum 1995; 38: 1519-1523.

12. Schwarz MI, Sutarik JM, Nick JA, Leff JA, Emlen JW, Tuder RM. Pulmonary capillaritis and diffuse alveolar hemorrhage. A primary manifestation of polymyositis. Am J Respir Crit Care Med 1995; 151: 2037-2040.

13. Nash P, Schrieber L, Webb J. Interstitial lung disease as the presentation of anti-Jo-1 positive polyomyositis. Clin Rheumatol 1987; 6: 282-286.

14. Löhr H-F, Böcher WO, Hermann E, et al. Interstitial alveolitis as early manifestation of anti-Jo-1 polymyositis. $Z$ Rheumatol 1993; 52: 307-311.

15. Flammang d'Ortho MP, Cadranel J, Milleron B, et al. Atteintes pulmonaires interstitielles des polymyosites (PM) et dermatopolymyosites (DP). A propos de 3 observations. Revue de la littérature. Rev Pneumol Clin 1991; 47: 29-36.

16. Chmiel JF, Wessel HU, Targoff IN, Pachman LM. Pulmonary fibrosis and myositis in a child with anti-Jo-1 antibody. J Rheumatol 1995; 22: 762-765.

17. The BAL cooperative group steering committee. Am Rev Respir Dis 1990; 141: S199.

18. Targoff IN, Arnett FC. Clinical manifestations in patients with antibody to PL-12 antigen (alanyl-tRNA synthetase). Am J Med 1990; 88: 241-251.

19. Goldstein R, Duvic M, Targoff IN, et al. HLA-D region genes associated with autoantibody responses to histidyltransfer RNA synthetase (Jo-1) and other translation-related factors in myositis. Arthritis Rheum 1990; 33: 1240-1248.

20. Targoff IN, Reichlin M. Measurement of antibody to Jo-1 by ELISA and comparison to enzyme inhibitory activity. $J$ Immunol 1987; 138: 2874-2882.

21. Dalakas MC. Current treatment of the inflammatory myopathies. Curr Opin Rheumatol 1994; 6: 595-601.

22. Joffe MM, Love LA, Leff RL, et al. Drug therapy of the idiopathic inflammatory myopathies: predictors of response to prednisone, azathioprine, and methotrexate and a comparison of their efficacy. Am J Med 1993; 94: 379-387.

23. Dankó K, Szegedi G. Cyclosporin A treatment of dermatomyositis. Arthritis Rheum 1991; 34: 933-934.

24. Mehregan DR, Su D. Cyclosporine treatment for dermatomyositis/polymyositis. Cutis 1993; 51: 59-61.

25. Grau JM, Herrero C, Casademont J, Fernandez-Sola J, Urbano-Marquez A. Cyclosporine A as first choice therapy for dermatomyositis. J Rheumatol 1994; 21: 381-382.

26. McCune J, Vallance DK, Lynch JP 3rd. Immunosuppressive drug therapy. Curr Opin Rheumatol 1994; 6: 262-272.

27. Al-Janadi M, Smith CD, Karsh J. Cyclophosphamide treatment of interstitial pulmonary fibrosis in polymyositis/dermatomyositis. J Rheumatol 1989; 16: 1592-1596.

28. Rowen AJ, Reichel J. Dermatomyositis with lung involvement, successfully treated with azathioprine. Respiration 1983; 44: 143-146.

29. Gruhn WB, Diaz-Buxo JA. Cyclosporine treatment of steroid resistant interstitial pneumonitis associated with dermatomyositis/polymyositis. J Rheumatol 1987; 14: 10451047.

30. Moolman JA, Bardin PG, Rossouw DJ, Joubert JR. Cyclosporin as a treatment for interstitial lung disease of unknown aetiology. Thorax 1991; 46: 592-595. 